\title{
Early career researchers' identity threats in the field: the shelter and shadow of collective support
}

\author{
Lisa Jane Callagher, Ziad El Sahn, Paul Hibbert, Stefan Korber, \\ and Frank Siedlok
}

\begin{tabular}{|c|c|}
\hline Date of deposit & 10 February 2021 \\
\hline Document version & Author's accepted manuscript \\
\hline Access rights & $\begin{array}{l}\text { Copyright (C) The Author(s) } 2021 \text {. This work is made available } \\
\text { online in accordance with the publisher's policies. This is the } \\
\text { author created, accepted version manuscript following peer } \\
\text { review and may differ slightly from the final published version. }\end{array}$ \\
\hline $\begin{array}{l}\text { Citation for } \\
\text { published version }\end{array}$ & $\begin{array}{l}\text { Callagher, L., El Sahn, Z., Hibbert, P., Korber, S., \& Siedlok, F. } \\
\text { ( } 2021) \text {. Early career researchers' identity threats in the field: the } \\
\text { shelter and shadow of collective support. Management Learning, } \\
\text { Online First. }\end{array}$ \\
\hline $\begin{array}{l}\text { Link to published } \\
\text { version }\end{array}$ & https://doi.org/10.1177/1350507621997738 \\
\hline
\end{tabular}

Full metadata for this item is available in St Andrews Research Repository at: https://research-repository.st-andrews.ac.uk/

St Andrews $|1413|$




\title{
Early career researchers' identity threats in the field:
}

\section{The shelter and shadow of collective support}

\begin{abstract}
Based on an autoethnographic study of early career researchers' field research experiences, we show how individuals deal with moments of discrimination that present identity threats. This is accomplished through participating in the construction of a shared holding environment to provide emotional shelter and resources for resultant identity work. We show how they collectively develop anticipatory responses to future identity threats and inadvertently how this allows the effects of discrimination to be both unchallenged and amplified. We draw implications for identity work theory, adding to current understandings of identity threats, tensions, and challenges and the dynamics through which these are addressed, avoided, or worked around, as well as the shadow side of such activities. We also offer practical implications about the business schools' role in nurturing early career researchers' identity work.
\end{abstract}

Keywords: identity, identity threats, identity work, business schools, field research 


\section{Early career researchers' identity threats in the field:}

\section{The shelter and shadow of collective support}

In this paper, we are concerned with how identity threats, experiences that "indicate potential harm to the value, meanings, or enactment of an identity" (Petriglieri, 2011: 641), impact early-career field researchers. Fieldwork sites are recognized as spaces for identity work (Alvesson, 2003), and early career researchers (ECRs) experience identity threats (Winkler, 2018), including those based on discriminatory incidents (Fernando et al., 2020) that have adverse effects on professional engagement. These challenges are experienced in addition to the general difficulties of identity work in academic contexts (Knights and Clarke, 2014; Shams, 2019) and the precarious and unstable situations of many ECRs (Bosanquet et al., 2017).

Field research is a challenge for ECRs because gaining access to gather suitable data can be difficult (Buchanan et al., 1988; Michailova et al., 2014; Peticca-Harris et al., 2016; Wright et al., 2020). ECRs may struggle to build trusting relationships with participants while presenting themselves as professional, experienced researchers (Dundon and Ryan, 2010). Approaches to address the initial difficulties of gaining and maintaining field access are well documented (Hammersley and Atkinson, 2007; Patton, 2002; Peticca-Harris et al., 2016), and focus on exploiting insider knowledge (Anteby, 2013; Brannick and Coughlan, 2007), cultivating key informants (Adler et al., 1986; Cunliffe and Alcadipani, 2016), or building an understanding of the field through peripheral engagement (Feldman et al., 2003; MacLean et al., 2006). However, discriminatory experiences restrict these strategies and affect identity work possibilities (Fernando et al., 2020), thereby obstructing the presentation of the early career researcher's desired professional identity. 
Identity work considers the processes through which individuals construct a congruent sense of self (Alvesson and Willmott, 2002; Brown, 2015; Watson, 2009). Outcomes are more-or-less coherently achieved identities involving personal, professional, managerial, and hybrid forms that may be resilient or precarious (McGivern et al., 2015; Petriglieri et al., 2019). Identity threats can trigger or disrupt identity work (Brown and Coupland, 2015; Petriglieri, 2011) and may be affected by enabling or constraining contexts (Brown, 2015). Besides, identity threats can be experienced differently in relation to personal characteristics such as ethnicity, gender, and age (Brown and Coupland, 2015; Fernando et al., 2020; Ladge et al., 2012; Perrott, 2019; Riach and Cutcher, 2014). In short, discrimination can be the basis, or an aspect, of experienced identity threats.

Individuals seek to address identity threats, tensions, and challenges in multiple ways. Some of the strategies employed to manage emotional stress and provide opportunities for desired future identity work include responding in kind (Koveshnikov et al., 2016) or exploiting or suppressing particular characteristics (Zanoni et al., 2017). Others involve compartmentalizing aspects of themselves or enacting desired identities at different times (Kennedy-Macfoy, 2013; Perrott, 2019; Shams, 2019), or constructing “personal holding environments" (Petriglieri et al., 2019: 153).

Desired identities are formative in early career stages, and projections of the future can be important. In such circumstances, the support of others in countering threats can help identity work (Beech, 2017). Still, the role of informal collectives in providing that support needs more study, to add to insights from studies of professional communities (McGivern et al., 2015), formal organizational teams (Cain et al., 2019), and precarious work environments (Petriglieri et al., 2019). Along these lines, Jonason (2019: 691) argues that the role of shared ideas about the future in diverse collectives has been overlooked as an unrecognized form of identity work that may affect the activities sustaining a collective. Thus, there is a need for 
more attention to how informal collectives develop in and through responses to identity work threats, how they influence future identity work, and how they are sustained. Our research question, therefore, is:

How do informal collectives for coping with identity threats develop, and how do they shape and sustain early-career researchers' projections of future identity work?

To address this question, the remainder of this paper proceeds in four main parts. First, we attend in more detail to the current literature on identity work, focusing on threats and tensions and responses to such challenges. Second, we set out our autoethnographic relationally reflexive (Hibbert et al., 2014) methodology for the study. The research was conducted within a business school where a diverse group of ECRs, seeking to establish and develop their careers, experienced discriminatory identity threats; this study involves authors from within the group. Third, we present our findings. We show how individual researchers respond in the moment of discrimination-based identity threats as they seek to complete their fieldwork. We show how they collectively participate in the development of a shared holding environment (Petriglieri et al., 2019) through identity-work activities and develop identity work approaches, with and through others, for future fieldwork. In the final section, we discuss the contributions for identity work theory related to the construction of a collectively shared holding environment, the establishment of a set of activities for resourcing future identity work, and the shadow side of addressing discrimination-based identity threats in such ways. We offer practical insights for international business schools (and others supporting diverse ECR communities) and argue that attention to identity work should form part of early-career academic development schemes. 


\section{IDENTITY WORK}

Identity work has been described as an ongoing process through which individuals “... are continuously engaged in forming, repairing, maintaining, strengthening or revising the constructions" of their sense of self to produce "coherence and distinctiveness" (Alvesson and Willmott, 2002: 626; and see Watson, 2009). Yet, the identity work that seeks to support this coherence is complex since it involves emotional and cognitive processes of contextualized language use, dramaturgical performances of gendered and embodied selves, and observation of how objects and symbols are appropriated and deployed (Brown, 2017; Conroy and O’Leary-Kelly, 2014; Ladge et al., 2012; Perrott, 2019; Riach and Cutcher, 2014).

The outcomes of identity work may be more-or-less coherently achieved identities that may be resilient or precarious (McGivern et al., 2015; Petriglieri et al., 2019). Such precarity is commonplace as individuals perform in a complex conceptual domain with uncertain boundaries and transitions, constructed through relationships between themselves and others (Beech, 2017). Identity work, thus, can seek to include the avoidance of undesirable identities, as well as the presentation of a desired self-image (Ladge et al., 2012). Besides, identity work may have teleological implications as it can be also be associated with the dynamics of developing, defending, or distancing oneself from committed goals (Grimes, 2018).

\section{Identity threats as triggers for, and constraints on, identity work}

Identity threats and tensions are well-recognized as triggers of identity work (Brown, 2015). For example, disruptive characterizations and attributions are especially troublesome when non-work identities are stigmatized as outside 'the norm' of everyday professions, jobs, and roles (Fernando et al., 2020; Lee and Lin, 2011; Wesely, 2002). These kinds of threats can also introduce or exacerbate tensions between the achievement of particular career identities 
and a broader sense of self which triggers further identity work that seeks to reconcile such tensions (Barker Caza et al., 2018). Thus, identity work can be problematic and constraining in any context when individuals feel that their identity has been invalidated or includes irreconcilable tensions (Beech, 2011; Beech et al., 2016; Ellis and Ybema, 2010; Grimes, 2018; Sveningsson and Alvesson, 2003). Constraining and hard-to-reconcile tensions are multiple. They include tensions between professional and team identities, particularly when the team context undermines professional identity work (Cain et al., 2019). Irreconcilable business and values orientations required to fulfill an organizational role (Carollo and Guerci, 2018) is another source of tension, as are those between work and family (Ladge and Little, 2019), and institutional logics (Shams, 2019).

Identity threats can also have a direct obstructive effect when associated with an experience of conflict. For example, conflict is associated with identity work in multicultural organizations, when some individuals use “...stereotypical talk, [which] refers to identity work whereby managers enact their stereotypical conceptions of 'the other' to bolster their self-image and 'inferiorize' 'the other'” (Koveshnikov et al., 2016: 1353). Similarly, individuals can experience identity asymmetry, when they “...feel misidentified — when they believe their colleagues do not recognize their work-related identities" (Meister et al., 2014: 488, also see Meister et al., 2017). Other ways that conflict in identity work can be experienced include perceived assaults on professional values and status (Kyratsis et al., 2017; McGivern et al., 2015), attacks on cherished ideas that are significant in individuals career narratives (Grimes, 2018), and organizational focus on metrics that are experienced as coercive (Knights and Clarke, 2014; Shams, 2019). Such experiences can be “...fraught with fear, anxiety, angst, and trepidation [and] reconciling identity tensions and conflict implies various negative emotions" (Winkler, 2018: 123). 


\section{Responding to identity threats, tensions, and challenges}

Individuals respond to identity threats and tensions in two ways (Petriglieri, 2011: 648): "identity-protection responses" that seek to diffuse, neutralize, deflect, ignore or defend identity against them, and "identity-restructuring responses" that seek to modify, rationalize and reconcile identity in the face of them. The particular response varies with the context in which it is experienced, the resources that individuals have available to undertake identity work, and the possibilities that the local context affords (Kyratsis et al., 2017; Tracey and Phillips, 2016).

Identity threats to the desired identity can lead professionals to enact protective responses through an increased focus on particular resources from their other identities (Brown and Coupland, 2015) or when the threat results from losing a work role. It may also include reduced self-awareness (cultivating 'numbness') (Shepherd and Williams, 2016). Addressing threats through protective responses can also involve attempts to shift the perceptions of the self or other, endurance through coping mechanisms such as social and emotional support, or escaping by quitting the problematic context (Meister et al., 2017). Restructuring responses to threats may be influenced by how mutable individuals feel their identities to be, whether they are open to patterns of identity play, refinement, and validation, and the degree of importance attached to the desired identity (Meister et al., 2014, 2017). However, individual trajectories may vary with positive and negative experiences changing over time, as identity work is used to weave different personal narratives that reflect individual differences (Bolander et al., 2019). In between the extremes of a focus on the familiar and a radical rethinking of identity work possibilities, various other responses to identity threats have been noted.

Approaches to working with ethnic and culturally-rooted challenges may also include reflecting back the challenge to an oppositional other, for example, through responding to 
stereotypical, derogatory talk, in the same manner, deploying reactive talk that critiques stereotypes, or using self-reflexive talk that locates the individual in a wider frame (Koveshnikov et al., 2016). More generally, individuals may decide to exploit or suppress a particular characteristic in their identity work (Zanoni et al., 2017), or compartmentalize aspects of themselves and enact identity work that, from situation to situation, presents different desired identities (Kennedy-Macfoy, 2013; Perrott, 2019; Shams, 2019). Similarly, where individuals have multiple work identities in play, they may seek to manage these over time through identity work that keeps them separate, distinct, and concisely expressed, or integrate them through identity work that aims towards a more complex and elaborate narrative (Barker Caza et al., 2018; Ellis and Ybema, 2010). The latter approach attempts to maintain a clear sense of self, while unwanted characterizations and attributions are resisted (Costas and Fleming, 2009; Sveningsson and Alvesson, 2003).

Complex narratives can include projections of the future that help to shape the focus of individuals' identity work (Jonason, 2019), for example, when individuals strive towards a sense of being “...fully alive in one's work” (Petriglieri et al., 2019: 150). But such aspirations are not always achieved. Ahuja et al. (2019) show that prospectively oriented identity work for those at a liminal, early stage of a professional career can involve positive personal strategies. Still, these may alternatively spiral into the development of a less hopeful, 'dejected' self that focuses on camaraderie in identity work rather than progress. Beech (2017) has suggested that individuals can develop approaches to handle future identity work tensions and boundary issues, mainly through seeking to develop a shared, reflexive stance. However, the future-oriented dynamics of such approaches are yet to be fully explored. As Jonason (2019, p. 691) argues "the processes of defining, aligning with, and negotiating future projections constitute previously unrecognized forms of identity work.". 


\section{ECR responses to threats, tensions, and challenges to academic identity}

As Brown (2015: 31) highlighted, "different organizational contexts vary in the scope, resources, and encouragement they offer people as they fashion their identities." We argue that the experiences of ECRs in the academy - a context characterized by collaboration and communal feelings but also one with a proliferation of conflicting demands and managerial controls and strongly associated with insecure identities (Clarke et al., 2012; Knights and Clarke, 2014) - can be particularly illuminating for understanding the interplay between collective support, a shared reflexive stance and the development of future-oriented identity work. ECRs' experience of identity threats in fieldwork presents an opportunity to develop insights about these dynamics. Fieldwork activities, such as interviews, are arenas for identity work (Alvesson, 2003). While prior research has highlighted some of the identity threats that researchers can face in fieldwork, such as differences in professional values and the asymmetry in power dynamics between researchers and interviewees (Welch et al., 2002), there is little research on how researchers, especially ECRs, deal with such incidents.

Understanding how ECRs deal with identity threats is crucial because the future development of identity work to support resilience is more difficult in precarious contexts (Petriglieri et al., 2019). This is especially the case for ECRs who face increasing precarity (Bosanquet et al., 2017). Employed on fixed-term Post-Doctoral positions or short-contract teaching or the tenure process, ECRs often occupy 'liminal' identities (Beech, 2011; Ellis and Ybema, 2010) as outsiders seeking to develop trusting relationships that confer (at least temporarily) the status of insider (Beech et al., 2009; Hibbert et al., 2007). Such precarity is exacerbated for non-white and immigrant ECRs who find themselves using identity resources to employ covering ('toning down') and accenting ('playing up') strategies, by drawing on available and non-threatening identities to avoid identity tensions associated with misidentification in their academic workplaces (Fernando et al., 2020). 
Responses to the contextual constraints and insecurity of academic life can include identity work to maintain conflicting self-presentations and to switch between them, dependent on the situation at hand (Shams, 2019). To some extent, those with unstable or precarious contexts can seek to construct their own "personal holding environments" (Petriglieri et al., 2019: 153), which help “...them manage the broad range of emotions stirred up by their precarious working lives and focus on producing work that let them define, express, and develop their selves" (Petriglieri et al., 2019: 124). However, our understanding of the processes underlying the emergence of such holding contexts and how they provide opportunities for collective support and contexts for developing future identity work is still emerging.

\section{METHODOLOGY}

Our study draws on the experiences of a research group based at a major international business school. Over time, the group has varied in size as academic staff joined and moved on, doctoral and master students graduated, and individual roles changed. All the group members were ECRs, involving eight academic staff, three doctoral students, two master students, and three research assistants. The group members describe their nationalities as follows: Austrian; Chinese; Dutch; Egyptian; English; French; German; New Zealand; Scottish; South African; Polish; and Taiwanese. Seven of the group identify as female, and nine as male. These characteristics of the group, mostly immigrants at the early career stage, provides us with a particularly suitable context to explore identity work (Fernando et al., 2020; Huopalainen and Satama, 2019). Four of the five authors of this paper are members of this group.

We adopted an autoethnographic, relationally reflexive (Hibbert et al., 2014) approach in which we co-create novel insights through analyzing direct experiences. The approach 
allows us to capture personal, emotional, and in-depth insights that otherwise might remain ignored (Huopalainen and Satama, 2019). We draw on the experiences of four of the authors, although described episodes involved other members of the broader research group.

Autoethnography is criticized for subjectivity and issues related to a researcher both producing and analyzing research materials (Huopalainen and Satama, 2019). By adopting the relationally reflexive approach (Hibbert et al., 2014), we mitigated those issues through three strategies. We involved a fifth author, who was more senior and external to the group, in the reflection and analysis process. We collaboratively discussed interpretations of individual experiences in the authorial team. We maintained ongoing engagement with external audiences and reviewers that challenged our assumptions by offering alternative interpretations of our observations (Thomas et al., 2009). Figure 1 illustrates the research process, including data collection and analysis.

Figure 1 about here

The first phase of the research focused on eliciting examples of perceived discrimination in fieldwork. Although we had many informal discussions about the challenges of collecting data in a foreign country before, we never acted upon these insights formally. We laughed them off or framed them as something that we must accept as part of the fieldwork. Only once we started to discuss these experiences with our fifth author, we began to question, challenge, and subsequently engage with these experiences (Cunliffe, 2002). Out of the discussions, an authorial team interested in exploring these experiences and their potential effects on our research efforts in more depth emerged.

In a second phase, we engaged in focused rounds of discussion to elicit detailed experiences of perceived discrimination, how we dealt with those, and what effect this had on 
us as researchers. The open discussion among us, sharing personal experiences and fears, resulted in a decision that each of the four early-career authors should write autoethnographic narratives of experienced discrimination in the context of engaging in research. As the career stage and the informal community already were emerging as important factors in our discussions, we have decided to focus on the research group and the four ECRs. To include the maximum variety of experiences, rather than suppressing detail through a too rigid approach, we set no length limits or format of the narratives.

In the third phase, we actively sought alternative interpretations to balance our subjectivity. Thus, the fifth author's role had changed from sharing experiences to provide an external viewpoint to question our interpretations and to highlight patterns that we did not clearly see as insiders (c.f. Fernando et al., 2020). We engaged in rounds of joint reflection, often broadly following the process of "pair interviewing" (Gilmore and Kenny, 2015: 56), although within a wider collective of five. Through these interviews, we sought to trigger "open dialogue and alternative interpretations to surface different voices and perspectives and to question what may be taken for granted" (Ripamonti et al., 2016: 58) and to probe each other's interpretations, questioning and interrogating the narratives (Cunliffe, 2003). This 'joint interviewing' revealed different, and perhaps richer, insights to those found in our initial attempts at being reflexive as individuals (c.f. Gilmore and Kenny, 2015).

The joint discussion and analysis of our individual accounts gave rise to initial conceptual themes as we integrated our experience with extant theory. Initially, these emerging themes stayed close to data and were labeled as in-the-moment responses and anticipated future responses to potential identify threats. While the former was consistent with prior literature that emphasizes individualized responses (e.g., Brown, 2015), the collective dynamics through which longer-term responses were formed and enacted through a 'shelter of the othered' grabbed our attention. Through further rounds of discussion and analysis, we identified three 
kinds of identity work-re-presenting, re-constructing, and re-imagining - that enabled a collective understanding of past identity threats. In turn, these generated a wider repertoire of anticipatory responses, designed to avoid confronting identity threats in fieldwork: distributing identity work across the team, repositioning an individual against different referent contexts, and reframing the research context to diminish the salience of individual differences.

In the fourth, ongoing, phase we continue to refine our emerging theoretical understanding through sharing the work with colleagues, at seminars and conferences, and opening to our assumptions being challenged and alternative interpretations being offered (Thomas et al., 2009). Consequently, our focus and understanding shifted from simply complaining about perceived discrimination to understanding how our identities and practices have been altered through the process. Moreover, we started to develop a more critical perspective on the shadow side of our sheltering activities and our complicity in the (re)production of the emotional effects of discrimination.

\section{EMPIRICAL INSIGHTS}

In this part of the paper, we set out our empirical insights. We arrange these in four subsections, focusing first on the ways that researchers initially responded when aspects of their identity were threatened. Second, we consider how researchers collectively sheltered each other to recover from these threats and playfully explore more positive possibilities. Third, we consider how sheltering helped researchers to anticipate subsequent identity threats and develop strategies to work around them collectively. Fourth, we touch on the emergence of a 'shadow side' to this positive mutual support pattern.

\section{Identity threats in fieldwork}


Researchers in our community faced a range of identity threats as they sought to progress their research projects with field research participants. These challenges were experienced in two ways: through talk and non-verbal signals.

Challenges through talk were encountered in public forum and interview situations where participants referred to a researcher's ethnicity or gender, sometimes in oblique ways -

"The three of us, me, Claire and Craig - the industrial partner who organized the gig - were standing in front of some fifteen managers from local companies. Being informal, as usual, Craig went on about our contributions to the day, weaving some news and politics into his comments. When attempting to make a point about me, a foreigner being involved in research on some local cooperatives, he looked at me and asked: "what boat did you get off?" The room went dead silent..."

(Viktor)

- and sometimes clearly directed towards a specific characteristic, such as gender -

We were invited to a half-day of strategic events that started with an Annual General Meeting and then a strategic session. There were about 50 people and were told in advance that people would be interested to know who we are and would be welcoming. Before the first session, between the sessions, and after the second session, there was a lot of networking, and as we were told to expect, a number of people came up to introduce themselves and find out who we were. While talking, it was suggested we talk to an older man who was well-known in the area. When the older man passed us, the person I was talking to waved him to join us and introduced me as a researcher. The older gentleman replied that he was known as 'the godfather' of the industry, that he was happy to see a new lady in the district, and had a son looking for a wife if I was interested. My sharp reply saying if only I wasn't married played to his gendering of my identity.

(Claire)

The participants' remarks of this kind threatened researcher identity by playing down the role of research and drawing attention to other identity aspects through stereotypes. The types of identity threats generated two contrasting responses from the researchers. One response was like a 'flight' response: to say and do nothing despite observing that other researchers and the audience were aware of the remarks' inappropriateness. The other response was like a 'fight' response and often involved humor. Both responses were workarounds to create immediate relief 'in the moment', and neither confronted the identity threat head-on. 
Other challenges were delivered through non-verbal signals. These were encountered through participants' body language, (lack of) gestures, and demeanor towards some researchers in our group. We experienced situations where one participant would direct their attention, for example, to the female researcher and ignore the male research partner, or vice versa, or ignore a researcher of a particular ethnicity as the following two quotations about a single incident show:

We were still in the early days of conducting interviews in pairs. We planned ahead that I will lead on this one since Claire led on the previous one. We got in, introduced ourselves, and sat down. Even before I launched with the introduction to the project and the first question, his attention seemed fixated on Claire. He would direct his questions to her, pretty much ignoring me. Claire picked up the ball and took over the interview. For a little bit, I tried to ask some follow-up questions - but this was kind of pointless. His answers were directed at Claire and not even answering the questions. I lost interest-I got to look at his walls, picking up clues about his life and interest. I stopped taking notes - instead just doodled until the end, then we had polite chit-chat and we went off. "That was pretty odd," I said to Claire once in the car. She nodded...

We sat down ready to start the formal part of the interview. But Ian kept looking at and talking to me, and he kind of ignored Viktor. I started the interview. It seemed like every time Viktor asked a question, Ian ignored him, so I kept asking the questions. Once we were in the car driving home, we talked about how Ian seemed to really focus on me.

(Claire)

These behaviors generated a range of responses that included trying to re-state or rephrase questions to engage the participants whose body language was negative or closed towards the researcher, or another researcher taking the lead in the interview situation. Initially, decisions about which member of the group would lead the interview were made before the interviews. Still, the participants' behaviors in such incidents meant that the lead interviewer role had to change because of the interviewer-participant dynamic, in which the focus of discrimination was not always predictable:

We decided who would lead, just to find out this was not the person the respondent wanted to talk to... So, we switch the roles quickly and adapt so the other person led 
the interview. It helps to get rapport and a more engaging conversation goingsomething that would be hard to achieve if I was the only person interviewing and the participant did not quite like that accent of mine... But it also helps in other ways: getting more in-depth discussions; sharing the cognitive load of paying attention; redirecting the discussion when it starts going off track. If I'm the sidekick, I have time to listen, to process, and to connect the story to other interviews; to interject.

The challenged researcher often took an observer's role, seeking to re-engage with the participants through follow-up questions. When some participants continued to ignore them, disengagement by the researcher was the only remaining response. Over time, it became a norm for the group to avoid making firm decisions on the lead interviewer until the interview was underway and the rapport between the participant and researchers could be gauged. All these responses were workarounds that attempted to complete the interview. However, none of them helped the researchers to deal with the identity threat in the moment or with similar situations in the future.

\section{In the shelter of others}

We now consider how researchers "sought shelter" in the form of support or protection from other researchers in the community, in the wake of identity threats. Our analysis revealed two types of sheltering activities: those that provided support to enable informal expressions of identity work, and those that inverted stigma to diminish the impact of discrimination.

Sheltering that enables informal professional talk: We identified two activities in this category. First, we utilized the emerging social network of "othered" researchers, to connect with researchers who faced similar challenges, to share their experiences, and to learn from one another. These activities are important elements of identity work (Fernando et al., 2020; Huopalainen and Satama, 2019), as articulated below:

"Pablo, one day, noted that the group is made up mostly of foreigners. I never really thought about it - but the group often provides support to each other by talking about the experiences and fears of getting into the field and through more social engagements. We often turn the discriminatory experiences into sarcastic comments related to each other's background and nationality, foregrounding the experiences and the issue: the German is being late again; maybe you should change your name 
to Helen. It does not take the issue away - but makes it easier to accept and find some productive ways to deal with. I don't really care anymore - I know I will get in [to the research sites]. But others might need to build some of that resilience."

(Viktor)

Shared experiences included encounters in the field during the research program, but also from research experience before joining the group:

I have always tried to avoid phone interviews. When I was collecting data for my Ph.D., I traveled to other countries several times just to sit for a few hours of interview, even when participants suggested to talk over the phone. When you are talking over the phone, your interlocutor's attention is fixated on your voice. They can only hear your voice and the way you speak. [...] Because of my strong accent, and previous experiences inside and outside of academia that made me feel a bit insecure about some aspects of my identity, ethnicity, and so on, I always tend to be very sensitive to how I think others might react. This feeling doesn't go away of course in face-to-face interactions, but still...

(Chang)

In contrast to such feelings of insecurity, the social network enabled researchers to feel comfortable expressing their national customs, to problematize research practices in their native countries or abroad, or to celebrate cultural festivals with other researchers. Through sharing experiences in which identity work had been challenged or negated, researchers could connect their researcher identity and other identities in constructive ways.

Through the social network, the wider community shared other discriminatory experiences that extended beyond data collection into other spheres of academic identity work. These included the challenges that some colleagues faced to gain travel visas for conferences, transiting airports for international conferences when traveling on certain passports, and considering academic job prospects. Although at times uncomfortable to share, the realization that others had faced similar struggles, and learning from them how to deal with those, proved to provide some immediate relief. Thus, these activities helped individuals to represent themselves as researchers, challenging the experiences that seemed to undermine their emerging professional identities. Sharing stories with new researchers joining the group, especially Master and Ph.D. candidates, about what others had done in those situations and 
talking about different ways to present oneself in similar situations was intended to help them avoid or better cope with such threats. This became an essential part of conversations within the group.

Sheltering that inverts stigma: The second supportive sheltering activity came in the form of light relief, through the humor that the community developed about their experiences. As the social network developed members made insider jokes about their ethnicity, nationality, accents, gender, and sexuality. The humor played on the discrimination the researchers themselves had experienced, for example, "Viktor, you'll be late for your boat" making light of the remarks we presented earlier. The humor extended to involve some of the common stereotypes of particular nationalities of the researchers in the group: "The German is late" or "Rick the American" when referring to their work styles as researchers. Alongside signaling of being an insider of the social network, the humor provided the support of both "laughing it off" and, at the same time, showing individuals they have the support of the community who sympathized with their experiences.

\section{Anticipating identity threats}

The sheltering activities described above established a context where researchers could engage in the development of anticipatory responses through playful and imaginative identity work. For this reason, they help to illuminate the development of professional identity work in the long-term. The sharing of experiences within the group led to a greater ability to anticipate identity threats and, subsequently, develop a repertoire of tactics and responses that helped them pre-emptively deal with these. They imagined themselves in the situations that other community members had experienced, and played out different response scenarios, learning vicariously and reflexively.

Anticipating through selective self-presentation: The group often shared tactics about (avoiding) presenting oneself through emails, handling phone calls, designing interview 
schedules, or exploiting the areas of local 'small talk' that can help to build rapport. Some of the tactics were also more interventionist in nature, as illustrated by this example:

Zhang Wei had good English comprehension, but he was still learning to comprehend local accents. I discussed with Zhang Wei, Viktor, and some other colleagues. We decided that I'd contact the companies and then pass the connection to Zhang Wei and I'd go with him to the first interview to support him so he could feel confident to present himself over time.

(Claire)

The group was aware of some of the potential challenges Zhang would face. Thus, developing these practical approaches helped researchers learn to prepare to enter the field to collect data and reduce the likelihood of facing identity threats. Over time, this led to researchers seeking feedback from others to shape their research interventions to fit the local context. This enabled the researchers to manage their presentation of self or deliberately refrain from this in multiple ways. For example, where a perceived threat related to the presentation of a non-Western name, email communications could be sent by a member of the team with a Western name or redirect queries to them:

We were ready to hit the road and get some participants lined up. Chang looked a bit uncomfortable when I suggested he contact the two companies we wanted to talk to. He asked me if I would mind doing it - because of the 'seniority' or title. Then, after a short pause, added 'and my name'. I agreed to chase them-laughing that my name is not exactly a local one either. To which he replied that 'at least it's not from 'that part' [of the world]. We got the companies on board.

(Viktor)

Research Assistant email communication to participant: It was great to talk earlier and thank you for offering to take part in the University research project into innovation within producer co-operatives. I have attached the Participant Information Form which outlines the high-level goals of our research and how the interview process would work. I have also cc'd in the lead researchers Dr. Claire Jones and Dr. Viktor Schmitt should you have any questions for them.

Approaching participants as a research group in this way allowed researchers to focus on identity work on being a team member, rather than being an individual researcher. In similar examples, by putting the team members' Western names first, the researchers learned to shelter each other by avoiding expected remarks about, or outright rejection because of, 
having non-Western names. Similarly, newer members would mention the job titles of more experienced team members ("I am calling on behalf of..." or "I am working with...", for example) in phone calls and emails to address the same anticipated threat. While these activities reduced the possibility for professional identity work (as an individual researcher) in selected media, they helped secure data for research projects and allow for possible later individual self-presentation once embedded in the field as part of the research group.

Similar choices about selective identity work focused on the team or the self were employed in anticipating participants' remarks about accents. For example, researchers with non-local accents asked colleagues with local accents to make phone calls to prospective participants to introduce the project and to invite them to participate:

Both Chang and Viktor were reluctant to make a call. So, we agreed that I will initiate and deal with calls to "nail that interview date", while they deal with emails.

(Claire)

The sheltering of others was important in developing such responses since it was through developing trusted connections in the social network that researchers were able to ask peers to 'front' an email or help them with a phone call, for example.

Over time, the group came to regularize research collaboration to enable selective self-presentation across a team. For example, conducting interviews in pairs emerged as an approach serendipitously:

The 'interview in a pair protocol' came somewhat accidentally... we realized that the approach works better ... it helps us to deal with the bias - whether a participant prefers to talk to a foreign male or a local female. ...... we would probably not realize the levels of gender and ethnic discrimination if we did not go in pairs in the first place.

This approach allowed field access and data collection to continue even if identity threats silenced or undermined one researcher. By observing researcher-participant interactions together, the researchers drew each other's attention to identity work challenges, which enabled them to switch roles during interviews and talk through the incident immediately 
after, as discussed earlier. For some of the researchers who had experienced multiple challenges, the collaborative approach to data collection enabled them to check their sensitivities in interpreting these threats with the companion researcher that was also present. They were also able to develop a "game plan" with the other researchers before interactions with participants, which included running through scenarios in advance and knowing which of the anticipated responses they might deploy. Thus, co-researcher techniques in explaining projects, contacting participants, and collecting data in pairs became common practice in our research community. In addition to mutual support, peer mentoring was also enabled through this approach.

Anticipating through changing the basis of self-presentation: Members of the group shared how those who had enough local knowledge could use small talk to build rapport with participants. This was perceived as a means to connect through non-professional (researcher) identity work, by positioning oneself with industry talk or possible shared recreational interests. This led to the emergence of a practice of using desk research to understand both the company and the participants before site visits and to recognize some of the technical terms and acronyms and use them during interviews to build rapport or establish credibility:

I hate networking and chit chat. Then there are the accents and lack of common interest that can make it awkward. We started to check what the participants are into, then you look for some clues about them when on site. You check the photos, memorabilia, you check what tractor or bike they ride. Then drop a comment to get them talking. Maximilian often started to chat about his country origins -beer talk. There is always some connection you can make.

(Viktor)

Viktor always asks what the company is working on, how does it work and what are the technical terms around. We often check YouTube to get an understanding of the technology. He subscribed to [Industry] Magazine to see what they are up to. We always drop in a suggestion to show us their workshop - and even suggested to do the interviews in there. Talk about farming or engineering gets them really going - they forget that we are from the 'business school' and we are foreigners. 
Over time, it became usual to build for researchers running the interviews a version of the self that was more closely aligned to the participant's interests and background. Knowing, for example, contacts and hobbies, researchers rehearsed different scenarios about when and how they might employ that information. For researchers whose accents were substantially different, they found that being able to talk about topics close to the participants' interests or comprehend and use technical jargon gave them the confidence to engage.

The sheltering of others was important to these activities. The social network-enabled researchers to talk informally about the approaches employed in data collection and made them aware of others who could help them to fill a gap in local knowledge (e.g. schooling, politics, sport, and so on). Alternatively, some researchers chose to change the basis of interaction to activities where they could enact professional academic identity work without having to face the potential discriminatory incidents. For example, they drew on their prior experiences to legitimize their researcher identity by referring to previous projects with companies known to the participant. Evoking insights from earlier interviews, mentioning the views of industry leaders on current industry issues, or using the industry jargon when explaining the project and asking questions were other tactics for legitimizing researcher identity too. The desired result of these activities was to change the basis of the connection between a group member and the research participants by shifting their self-presentation from field researcher (at least for a time) to an industry partner, social contact, or back-room specialist. Practically, the research could continue in this way - although preferred identity work as a researcher was not necessarily enabled.

Anticipating through changing the referents for self-presentation: Researchers also developed other responses to anticipated remarks about their non-local identity, by focusing on the team or on alternative aspects of the self that had broader significance and salience. Some would stress the project origins as being important to broader regional or international 
issues (connected to, for example, ideas and debates occurring in practitioner contexts), while others would stress a non-local researcher's experience (especially in high-profile international contexts) as important for the project:

\begin{abstract}
I noted that Claire would often highlight what I did back in Europe and make the research experience sound really grand - almost embarrassing. Then during the last session, I went to with Chang - I caught myself doing the same. It is kind of implicitbut I guess some of it might be to pre-empt the potential bias and give ourselves some extra weight?
\end{abstract}

(Viktor)

The former response sought to legitimize the topic of the projects as ones that are of broad interest and thus justifying the interest of international researchers. The latter response sought to legitimate the non-local researcher as a professional with expertise, perhaps with aspects of international debates relevant to the wider context of the industry. Both approaches presented the researchers' identity work within a wider framing of the focal industry and as part of broader international trends. These tactics sought to shift the conceptual boundaries in which the interview took place to describe a more accommodating space for their research within it.

\title{
The emergence of a shadow side
}

The findings above show how collaborative processes helped researchers deal with identity threats arising from discrimination in the field, provided (mutual) shelter from the emotional and practical effects of discriminatory incidents, and enabled anticipated responses to future identity threats. We initially thought that these were unambiguously positive insights, but as our reflexive conversations continued, we began to question whether this supportive context for field research had a shadow side. In turn, we started to realize that the constant discussion of perceived identity threats can give rise to taken-for-granted explanations for the challenges we face. For example, we might have started to interpret all experiences as identity threats and became less open to alternative explanations for research participants' behaviors. By focusing mainly on the unpleasant aspects of fieldwork, new researchers in the group may become too sensitive to the potential issues and develop an overly negative picture of the 
domestic context. While the experiences we have described confirm that discrimination in the field is an issue, it is possible that we are leading ECRs to 'experience these threats in advance'; heightening fear and anxiety, potentially undermining normal engagement in the field, and perhaps missing other ways of handling discrimination that can help to disrupt it, as these examples from Chang and Viktor show:

I was planning to keep my participation in this interview to a minimum, but then interestingly, when one of the two managers started talking, and he had a non-native accent, I found myself getting in the discussion and stopped worrying about my own accent!

(Chang)

It always attracts the question 'where are you from', with a second guess of some random country. Sometimes I ask them to guess, sometimes I answer in a riddle-like manner. Often respondents look for some connection - so I help them to find one...

We had established a supportive network, but also created a climate of fear with selfpresentation, leading to strong anticipation of identity threats. The further discussion showed that these fears were more pronounced among some of the team members than others. The emergence of this shadow side, and the ways in which support for professional identity work might, in fact, be undermining, continues to be a focus of our reflexive conversations.

\section{DISCUSSION AND CONCLUSION}

We studied how ECRs responded to identity threats, leading to insights about how collective support for coping with these threats developed, how this shaped projections of future identity work, and, how such spaces can have a shadow side that facilitates the reproduction, and to an extent the amplification, of identity threats. Our findings regarding how ECRs deal with identity threats 'in the moment' is consistent with prior literature (Brown, 2015) in that ECRs responded to these threats by either ignoring, replying satirically, or disengaging when an alternative interviewer was present. Such responses allowed the functional purpose of the interview to continue but left feelings of unease and complicity and introduced an identity 
work tension (Beech, 2011; Beech et al., 2016) between professional and team identities. The functional effectiveness of the research team was maintained, but further undermined the professional identity work of one of the team members (Cain et al., 2019). The precarious conditions of employment of some ECRs and the institutional demands of producing publications (Bosanquet et al., 2020; Smith, 2010) led them to adopt non-confrontational approaches to threats to ensure fieldwork access and project completion.

Our main contribution is concerned with the collective dynamics through which longer-term responses were formed, explicating how the context of fieldwork and the broader institutional conditions of academia led ECRs to adopt non-confrontational strategies. There are three main elements. First, we explain how a support network, constructed through efforts to cope with the emotional difficulties and consequences of past identity threats encountered in fieldwork, provided a holding environment (Petriglieri et al., 2019) that offered shelter. Second, we describe how activities oriented towards the past within the shelter space influenced projections of future identity work, with consequences for where and how this was practiced. The sense of a shared holding environment constructed by the network led to sheltering activities that protected colleagues from projected identity threats, through enacting identity work in collaboration with others to enable selective self-presentation. Third, we identified the 'shadow side' of sheltering in which aspects of the emotional experiences were noticeable but often avoided or ignored (Clancy and Vince, 2019). By developing shared projections about the future and responses that are performed with and through others to avoid confrontation, the identity threats that stimulated the construction of the shelter space remained unchallenged. This absence of confrontation has consequences for the continuation of a social problem. It suggests a need for further attention towards how discrimination might be addressed by those who feel they are in precarious positions.

\section{The shelter space as a shared holding environment}


Increased precarity and mobility among ECRs mean that a growing number "seem to inhabit “in between" spaces" (Ibarra and Obodaru, 2016: 48), such as Postdocs and immigrant academics (Fernando et al., 2020). This results in new forms of under-institutionalized liminal experiences (Ibarra and Obodaru, 2016) for ECRs, which compared to traditional academic career trajectories, lack the highly ritualized path and institutional guidance and support due to their unique experiences. In such conditions, it is argued that supporting communities can be self-constructed (Ibarra and Obodaru, 2016) to act as a personal holding environment (Petriglieri et al., 2019).

In our study, the shelter network was initiated through mutual attachment based on common experiences of discriminatory challenges forming a network of the 'othered'. The network provided a space for the intersubjective temporal reconstruction of past discriminatory experiences and collective strategizing for future responses through a process of identity play (Ibarra and Obodaru, 2016; Ibarra and Petriglieri, 2010). This enhances our understanding of the temporality of identity work (Brown, 2015) and the possibility of collective action in enabling identity work in other spheres of academic life (Hökkä et al., 2017). Through sharing past discriminatory experiences, ECRs reconstructed these events to create a shared story based on which future responses to identity threats were developed. The shelter network, therefore, enabled ECRs to develop their collective agency whereby they “exert influence, make choices, and take stances in ways that affect their work and their professional identities ... [by developing] new work practices, or their collective efforts to negotiate a new shared understanding of themselves as a professional group amid external challenges" (Hökkä et al., 2017: 38).

The collective and socially-supportive aspects of the network add nuances to Petriglieri et al.'s (2019, p. 124) insights about the individual construction of "personal holding environments" that help precarious workers to "manage the broad range of emotions 
stirred up by their precarious working lives and focus on producing work that let them define, express, and develop their selves." Specifically, we found that the shelter network formed a collective and shared holding environment, constructed through three kinds of activity: reinforced the sense of a 'safe space'; underlined the meaningfulness of identity work within the space; and provided a basis for future expectations. In this way, the network established a holding environment with a sense of space, shared meaning, and temporal extension, through activities we characterize as re-presenting, re-constructing, and re-imagining.

(i) Re-presenting: Dealing with the emotional difficulties of discriminatory identity work challenges was accomplished through the establishment, in social contexts, of ways in which the identity work challenges were treated ironically, stigmatized identity elements were celebrated (c.f. Zanoni et al., 2017), and coherence was made possible through informal talk on professional themes and challenges. The network developed characteristics of a holding environment (Petriglieri et al., 2019), becoming a resonant 'safe' space for relatively unconstrained identity work that allowed members to present themselves as they wish, in which otherness was expected and destigmatized.

(ii) Re-constructing: The network's functions as a holding environment included serving as a meaningful space through the intersubjective reconstruction and sharing of past incidents. This led to the emergence of a collective understanding of the network members' identity threats and a common sense of unity-in-otherness, forming a shared and loose conceptual boundary around those inside the shared holding environment.

(iii) Re-imagining: The network became a creative space through the effects of unconstrained identity work and shared (but diverse) otherness; members were able to think and experiment with different ways of dealing with identity threats and "provisional trials of possible future selves" (Ibarra and Obodaru, 2016: 56). Whereas identity work is conducted in the real world, identity play that involves trial and experimentation of possible future 
selves offers "a threshold between current reality and future possibilities" (Ibarra and Petriglieri, 2010: 11). As such this process of identity play generated a wider repertoire of responses to identity threats in fieldwork, but crucially this repertoire included collaborative responses that strengthened the salience of the network as a holding environment with a temporal dimension and its role in shaping prospective identity work.

\section{Sheltering as collaborative support for prospective identity work}

The identity work that goes on in re-presenting, re-constructing, and re-imagining shapes the shelter space, as a holding environment in which these activities are possible. Still, it also enables a move from recovery from the past to projections about the future. Expanding on prior studies that documented individually performed identity work processes such as accenting, covering (Fernando et al., 2020), accepting, complying, resisting, and joining (Alvesson and Willmott, 2002; Brown, 2015), we found that sheltering also involves identity work performed with and through others.

Supportive processes influence how responses to future discriminatory identity work challenges are anticipated. Anticipatory responses can include the suppression or hiding of ethnic, gendered, or other embodied identity work forms that are expected to encounter discrimination or stereotyping (Koveshnikov et al., 2016; Meister et al., 2014, 2017; Perrott, 2019; Riach and Cutcher, 2014). But this suppression works in tandem with other processes that are necessary for the research to proceed: distributing identity work across different team members and multiple media/contexts, repositioning an individual against different referent contexts, and reframing the research context to diminish the salience of individual differences.

Thus, when suppression is achieved through the careful use of media to avoid disclosure of the personal identity work that normally accompanies professional identity work in a coherent self-construction (McGivern et al., 2015; Petriglieri et al., 2019), for 
example, using email to avoid disclosing a non-local accent, it also involves distributing identity work to those who follow up by voice or in-person contact. The identity work experienced by the research participant creates a composite impression of the group that excludes the characteristics that team members anticipate could be met with discrimination. Similarly, choosing a local team member able to make personal connections with contacts through social small talk can build trust as a bedrock for broader identity work (Driver, 2015), reducing the tension of the situation and making other ECRs' identity work less constrained.

Repositioning is accomplished through a deliberate talk to provide a reframing of status signals (Kyratsis et al., 2017) in the history of 'othered' team members as experts and to increase their personal standing in a potentially discriminatory context. Reframing could be accomplished by generating a focus on the broader international context of the industry that was a focus of the project (c.f. Kyratsis et al., 2017) to sidestep identity work issues. By generating a sense of a wider context in which the researchers and participants had joint aims in comparison to more a new group of 'others' the differences present in the local context become less salient, thereby bringing parties into the same conceptual space stretching across identity differences (Beech, 2017).

\section{The shadow side of sheltering}

Dealing with the practical difficulties of discriminatory identity threats involves the sharing of approaches that do not confront the challenges head-on but instead allow shared project aims (Beech, 2017) associated with the professional identity to be achieved despite the difficulties experienced. While the formulation of workarounds can have benefits for the shared projects, such as a stronger sense of common goals and taking pressure off the researchers involved in data collection, the support network did not assist individuals in challenging the identity threats and calling out the discriminatory behavior. On the contrary, 
the support network became somewhat complicit in reproducing, and to an extent amplifying, identity threats. While the anticipatory responses developed through supportive networks were found to be effective in meeting the needs of the research program and providing the material that was necessary to all participants, they have clear downsides. Significantly, they develop a double pessimism about the likelihood of discriminatory challenges to the identity work of professional researchers and the powerlessness of 'the othered' to confront these challenges head-on. Developing shared views of potential identity threats and adopting nonconfrontational strategies perpetuates the effects of discrimination. By sheltering ourselves, we throw a shadow that allows such behaviors to remain hidden. At the same time, through re-presenting, we might be desensitizing ourselves to those behaviors, thus not taking action when appropriate.

It is plausible that such a strong network can lead to exaggerated fears and perpetuation of past experiences that can be manifested in the amplification of negative stereotypes. Thus, new researchers might be already approaching the field with a rather distorted view of the field and anticipate discriminatory behaviors, which might not exist. These problems are exacerbated by the effects of normal and well-intentioned, developmental practices for early-career academics. Sharing is established in a peer-to-peer mode or through more experienced members of a network adopting a mentoring stance to those at an earlier stage in their career development. Commitment to common issues and shared processes of building resilience tends to lead to a common approach. Locked-in ideas about how and when particular elements of professional identity work are enacted (or restricted, in favor of project outcomes) are therefore likely, especially when there is also a common vision of the future (Jonason, 2019) and what a successful professional identity looks like (Knights and Clarke, 2014). Those in precarious positions - as many ECRs are - have less opportunity to carve out alternative responses and pathways and instead will rely on holding environments to manage 
the emotional stress associated with identity work in such conditions (Petriglieri et al., 2019). We illustrate the dynamics leading to these shadow-side outcomes in Figure 2.

Figure 2 about here

In summary, we have shown that informal collectives for coping with identity threats are developed through identity work activities of re-presenting, re-constructing, and reimagining. We extend Petriglieri and colleagues' (2019) work by showing how individuals make the connections that create shared holding environments that differ from the personal and formal organizational types that are the basis of their discussion. We also add to their insights by showing how prospective identity work (building on Jonason, 2019), involving distributing, repositioning, and reframing, leads to the continued existence of these shared holding environments as individual members may come and go. We also characterize negative effects not foreseen by Petriglieri and colleagues (2019), who found holding environments to be generative. The shared holding environment did allow tactics to be devised that allowed research objectives to be fulfilled, but such tactics also narrowed the scope of identity work and trammeled the professional activities of ECRs. Also, the approach involved reliance on the shared holding environment and did not support the disruption of the sources of discriminatory identity work threats. Neither did it address underlying feelings of precarity or insecurity, leading to unresolved professional-personal identity work tensions (to a degree, like the work-family identity confusions identified by Ladge and Little (2019)).

\section{Future research}

In acknowledging this shadow side to well-meaning support activities, we open space for future research on how self-supporting ECR networks may continue to develop to confront identity threats better. For example, there is scope for further research to consider how strategies such as reactive talk, "disclosing the falseness and superficiality of the invoked and 
applied stereotypes" (Koveshnikov et al., 2016: 1366), and the incorporation of reflexivity into such approaches as advocated by Beech (2017), might be enacted in practice. Reactive talk strategies, such as talking up expertise and pointing out the breadth of international experience, offer ways to raise the consciousness of researchers and participants alike.

However, future research also needs to consider the inherent risks of such strategies for those in an early career stage who, especially, encounter "identity work as an emotional experience [...] fraught with fear, anxiety, angst, and trepidation" (Winkler, 2018: 123). We speculate that the possibilities that follow from repositioning an individual by evoking history and expertise and reframing the research context such that local differences lose a degree of salience may have a role in helping ECRs develop further strategies, which in turn enables more assertive engagement and authentic identity work. We also speculate that if discriminated ECRs succeed in academia and gain seniority that may help to change the landscape in a way that automatically confronts the problem, or at least removes some of the anxiety in doing so. Investigating these speculations could involve research on how supportive networks may continue in the long term, grow, become formalized, and gain visibility.

\section{Insights for research practice}

Our findings have immediate implications for ECRs struggling to understand and adapt to identity threats faced in fieldwork, and our discussion showed how building collective support can assist them in practical ways. First, developing support networks with local and non-local researchers is important for resourcing identity work; it can help them develop a wider repertoire of responses that make them feel less insecure in the field. 'Local' researchers, embedded in their own communities and family networks due to their length of residence and tenure, might feel less need to develop new connections. Yet, they need to recognize that non-local researchers need time and support to build such ties. 
The second implication is the role that collaborative research can play in ECR development. Beyond the traditional reasons to collaborate, such as addressing skills or knowledge gaps through working with those with complementary abilities (Hibbert et al., 2016), our experiences show there are multiple ways in which research collaboration can support identity work while addressing the practical difficulties of fieldwork. While some responses reinforce the team's effectiveness to ensure field access, such as through the careful distribution of tasks, they can do this by diminishing individuals' identities and shadowing the very behaviors that present identity threats in the first place. For instance, a non-discriminated partner in dual interviewer contexts can take the lead during an interview to secure data collection, but this can reinforce the 'embodied absence' of the other researcher. This presents difficult compromises that need to be considered carefully through relationally reflexive engagement amongst research team members (Hibbert et al., 2019).

Beyond showing ECRs how they can support each other, our study has practical implications for business schools. Those universities active in recruiting non-local ECRs and doctoral students to internationalize their offerings have a responsibility to support the identity work of ECRs. Besides general newcomer socialization, helping non-local ECRs understand the challenges and responses required for coherent identity work is important. Thus, providing professional development that helps understand the role of identity work needed to respond to identity threats should be part of broader researcher training programs. These strategies may include some of the collaborative activities detailed in this paper, either for practical research purposes or the establishment of support networks that provide sheltering spaces and activities. However, there is a need to ensure that discriminatory identity threats are called out and that ECRs are supported.

We recognize that business schools are in a difficult position; providing training and support that talks honestly about identity threats and the compromises made in response to 
them can be seen in some ways as condoning discrimination instead of disrupting it. However, failing to provide any information or support will not make such identity threats go away - but it will continue to leave ECRs with problems to address by themselves when they encounter them in their field research. Therefore the sector needs to work together to make institutional interventions that bring these issues into policy discourse and consider how ECRs can be resourced to confront discrimination confidently and safely in ways that allow them to feel that their (sense of) self is accepted and respected.

\section{Concluding remarks}

Building on current identity work literature about the identity threats, tensions, and challenges that ECRs experience, we have shown how individuals react to unexpected moments of discrimination that create identity threats, explaining how this produces a sense of inferiorization and inhibits the enactment of professional identities. In studying how we as ECRs responded to these threats, we added to the literature by showing how collective support provided sheltering spaces where identity work from past identity threats was developed and how sheltering activities shaped prospective identity work. Finally, we also showed the shadow side of sheltering, offering suggestions and calling for more research to explore how the shadow side might be disrupted as a means to challenge discrimination and support ongoing ECR identity work. Our practical insights for ECRs and international Business Schools show the value of support networks supporting prospective identity work. However, moral questions about how discrimination is best-disrupted remain. As an authorial team with first-hand experiences of discrimination in the research field, we firmly believe that this merits further attention. Still, we also appreciate that simple answers are unlikely. 


\section{References}

Adler P, Adler P and Rochford Jr E (1986) The politics of participation in field research. Urban Life 14(4): 363-376.

Ahuja S, Heizmann H and Clegg S (2019) Emotions and identity work: Emotions as discursive resources in the constitution of junior professionals' identities. Human Relations 72(5): 988-1009.

Alvesson M (2003) Beyond Neopositivists, Romantics, and Localists: A Reflexive Approach to Interviews in Organizational Research. Academy of Management Review 28(1): 13-33.

Alvesson M and Willmott H (2002) Identity Regulation as Organizational Control: Producing the Appropriate Individual. Journal of Management Studies 39(5): 619-644.

Anteby M (2013) Relaxing the Taboo on Telling Our Own Stories: Upholding Professional Distance and Personal Involvement. Organization Science 24(4): 1277-1290.

Barker Caza B, Moss S and Vough H (2018) From synchronizing to harmonizing: The process of authenticating multiple work identities. Administrative Science Quarterly 63(4): $703-745$.

Beech N (2011) Liminality and the practices of identity reconstruction. Human Relations 64(2): 285-302.

Beech N (2017) Identity at Work: An Enquiry-based Approach to Therapeutically Inspired Management: Identity at Work. International Journal of Management Reviews 19(3): 357-370.

Beech N, Hibbert P, MacIntosh R, et al. (2009) 'But I thought we were friends?' Life cycles and research relationships. In Organizational Ethnography: Studying the Complexities of Everyday Life (pp. 196-214). In: Ybema S, Yanow D, Wels H, et al. (eds) Organizational Ethnography: Studying the Complexities of Everyday Life. London: Sage, pp. 196-214.

Beech N, Gilmore C, Hibbert P, et al. (2016) Identity-in-the-work and musicians' struggles: the production of self-questioning identity work. Work, Employment and Society 30(3): 506-522.

Bolander P, Holmberg I and Fellbom E (2019) Learning to become manager: The identity work of first-time managers. Management Learning 50(3): 282-301.

Bosanquet A, Mailey A, Matthews K, et al. (2017) Redefining 'early career' in academia: a collective narrative approach. Higher Education Research \& Development 36(5): 890902.

Bosanquet A, Mantai L and Fredericks V (2020) Deferred time in the neoliberal university: experiences of doctoral candidates and early career academics. Teaching in Higher Education 25(6): 736-749.

Brannick T and Coughlan D (2007) In Defense of Being "Native": The Case for Insider Academic Research. Organizational Research Methods 10(1): 59-74.

Brown A (2015) Identities and Identity Work in Organizations. International Journal of Management Reviews 17(1): 20-40.

Brown A (2017) Identity work and organizational identification. International Journal of Management Reviews 19(3): 296-317.

Brown A and Coupland C (2015) Identity Threats, Identity Work and Elite Professionals. Organization Studies 36(10): 1315-1336.

Buchanan D, Boddy D and McCalman J (1988) Getting in, getting on, getting out, and getting back. In: Bryman A (ed.) Doing Research in Organizations. London: Routledge.

Cain C, Frazer M and Kilaberia T (2019) Identity work within attempts to transform healthcare: Invisible team processes. Human Relations 72(2): 370-396.

Carollo L and Guerci M (2018) 'Activists in a Suit': Paradoxes and Metaphors in Sustainability Managers' Identity Work. Journal of Business Ethics 148(2): 249-268. 
Clancy A and Vince R (2019) "If I Want to Feel My Feelings, I'll See a Bloody Shrink": Learning from the Shadow Side of Experiential Learning. Journal of Management Education 43(2): 174-184.

Clarke C, Knights D and Jarvis C (2012) A Labour of Love? Academics in Business Schools. Scandinavian Journal of Management 28(1): 5-15.

Conroy S and O'Leary-Kelly A (2014) Letting go and moving on: Work-related identity loss and recovery. Academy of Management Review 39(1): 67-87.

Costas J and Fleming P (2009) Beyond dis-identification: A discursive approach to selfalienation in contemporary organizations. Human Relations 62(3): 353-378.

Cunliffe A (2002) Reflexive Dialogical Practice in Management Learning. Management Learning 33(1): 35-61.

Cunliffe A (2003) Reflexive inquiry in organizational research: questions and possibilities. Human Relations 56(8): 983-1003.

Cunliffe A and Alcadipani R (2016) The Politics of Access in Fieldwork: Immersion, Backstage Dramas, and Deception. Organizational Research Methods 19(4): 535-561.

Driver M (2015) How trust functions in the context of identity work. Human Relations 68(6): 899-923.

Dundon T and Ryan P (2010) Interviewing Reluctant Respondents: Strikes, Henchmen, and Gaelic Games. Organizational Research Methods 13(3): 562-581.

Ellis N and Ybema S (2010) Marketing identities: Shifting circles of identification in interorganizational relationships. Organization Studies 31(3): 279-305.

Feldman M, Bell J and Berger M (2003) Gaining Access: A Practical and Theoretical Guide for Qualitative Researchers. Oxford: Altamira Press.

Fernando M, Reveley J and Learmonth M (2020) Identity work by a non-white immigrant business scholar: Autoethnographic vignettes of covering and accenting. Human Relations 73(6): 765-788.

Gilmore S and Kenny K (2015) Work-worlds colliding: Self-reflexivity, power and emotion in organizational ethnography. Human Relations 68(1): 55-78.

Grimes M (2018) The pivot: How founders respond to feedback through idea and identity work. Academy of Management Journal 61(5): 1692-1717.

Hammersley M and Atkinson P (2007) Ethnography: Principles in Practice. 3rd ed. London: Routledge.

Hibbert P, MacIntosh R and McInnes P (2007) Identity Trajectories in Participative Organizational Research. In: Beech N, Linstead A, and Sims D (eds) Researching Identity: Concepts and Methods. London: Routledge, pp. 237-250.

Hibbert P, Sillince J, Diefenbach T, et al. (2014) Relationally Reflexive Practice A Generative Approach to Theory Development in Qualitative Research. Organizational Research Methods 17(3): 278-298

Hökkä P, Vähäsantanen K and Mahlakaarto S (2017) Teacher educators' collective professional agency and identity - Transforming marginality to strength. Teaching and Teacher Education 63: 36-46.

Huopalainen A and Satama S (2019) Mothers and researchers in the making: Negotiating 'new' motherhood within the 'new' academia. Human Relations 72(1): 98-121.

Ibarra H and Obodaru O (2016) Betwixt and between identities: Liminal experience in contemporary careers. Research in Organizational Behavior 36: 47-64.

Ibarra H and Petriglieri J (2010) Identity work and play. Journal of Organizational Change Management 23(1): 10-25.

Jonason A (2019) Defining, Aligning, and Negotiating Futures: New Forms of Identity Work in an Urban Farming Project. Sociological Perspectives 62(5): 691-708. 
Kennedy-Macfoy M (2013) 'It's important for the students to meet someone like you.' How perceptions of the researcher can affect gaining access, building rapport and securing cooperation in school-based research. International Journal of Social Research Methodology 16(6): 491-502.

Knights D and Clarke C (2014) It's a Bittersweet Symphony, this Life: Fragile Academic Selves and Insecure Identities at Work. Organization Studies 35(3): 335-357.

Koveshnikov A, Vaara E and Ehrnrooth M (2016) Stereotype-based managerial identity work in multinational corporations. Organization Studies 37(9): 1353-1379.

Kyratsis Y, Atun R, Phillips N, et al. (2017) Health systems in transition: Professional identity work in the context of shifting institutional logics. Academy of Management Journal 60(2): 610-641.

Ladge J and Little L (2019) When expectations become reality: Work-family image management and identity adaptation. Academy of Management Review 44(1): 126-149.

Ladge J, Clair J and Greenberg D (2012) Cross-domain identity transition during liminal periods: Constructing multiple selves as professional and mother during pregnancy. Academy of Management Journal 55(6): 1449-1471.

Lee Y-H and Lin H (2011) 'Gaming is my work': Identity work in internet-hobbyist game workers. Work, Employment and Society 25(3): 451-467.

MacLean T, Anteby M, Hudson B, et al. (2006) Talking Tainted Topics: Insights and Ideas on Researching Socially Disapproved Organizational Behavior. Journal of Management Inquiry 15(1): 59-68.

McGivern G, Currie G, Ferlie E, et al. (2015) Hybrid manager-professionals' identity work: the maintenance and hybridization of medical professionalism in managerial contexts. Public Administration 93(2): 412-432.

Meister A, Jehn K and Thatcher S (2014) Feeling misidentified: The consequences of internal identity asymmetries for individuals at work. Academy of Management Review 39(4): 488-512.

Meister A, Sinclair A and Jehn K (2017) Identities under scrutiny: How women leaders navigate feeling misidentified at work. The Leadership Quarterly 28(5): 672-690.

Michailova S, Piekkari R, Plakoyiannaki E, et al. (2014) Breaking the Silence About Exiting Fieldwork: A Relational Approach and Its Implications for Theorizing. Academy of Management Review 39(2): 138-161.

Patton M (2002) Qualitative Research and Evaluation Methods. 3rd ed. Thousand Oaks: Sage.

Perrott T (2019) Doing hot and 'dirty' work: Masculinities and occupational identity in firefighting. Gender, Work \& Organization 26(10): 1398-1412.

Peticca-Harris A, deGama N and Elias S (2016) A Dynamic Process Model for Finding Informants and Gaining Access in Qualitative Research. Organizational Research Methods 19(3): 376-401.

Petriglieri G, Ashford S and Wrzesniewski A (2019) Agony and Ecstasy in the Gig Economy: Cultivating Holding Environments for Precarious and Personalized Work Identities. Administrative Science Quarterly 64(1): 124-170.

Petriglieri J (2011) Under Threat: Responses to and the Consequences of Threats to Individuals' Identities. Academy of Management Review 36(4): 641-662.

Riach K and Cutcher L (2014) Built to last: aging, class, and the masculine body in a UK hedge fund. Work, Employment and Society 28(5): 771-787.

Ripamonti S, Galuppo L, Gorli M, et al. (2016) Pushing Action Research Toward Reflexive Practice. Journal of Management Inquiry 25(1): 55-68. 
Shams F (2019) Managing academic identity tensions in a Canadian public university: the role of identity work in coping with managerialism. Journal of Higher Education Policy and Management 41(6): 619-632.

Shepherd D and Williams T (2016) Hitting Rock Bottom After Job Loss: Bouncing Back to Create a New Positive Work Identity. Academy of Management Review 43(1): 28-49.

Smith J (2010) Forging identities: the experiences of probationary lecturers in the UK. Studies in Higher Education 35(5): 577-591.

Sveningsson S and Alvesson M (2003) Managing managerial identities: Organizational fragmentation, discourse and identity struggle. Human Relations 56(10): 1163-1193.

Thomas R, Tienari J, Davies A, et al. (2009) Let's Talk about "Us" A Reflexive Account of a Cross-Cultural Research Collaboration. Journal of Management Inquiry 18(4): 313-324.

Tracey P and Phillips N (2016) Managing the consequences of organizational stigmatization: Identity work in a social enterprise. Academy of Management Journal 59(3): 740-765.

Watson T (2009) Narrative, life story and manager identity: A case study in autobiographical identity work. Human Relations 62(3): 425-452.

Welch C, Marschan-Piekkari R, Penttinen H, et al. (2002) Corporate elites as informants in qualitative international business research. International Business Review 11(5): 611-628.

Wesely J (2002) Growing up sexualized: Issues of power and violence in the lives of female exotic dancers. Violence Against Women 8(10): 1182-1207.

Winkler I (2018) Identity Work and Emotions: A Review. International Journal of Management Reviews 20(1): 120-133.

Wright A, Middleton S, Hibbert P, et al. (2020) Getting on with Field Research Using Participant Deconstruction. Organizational Research Methods 23(2): 275-295.

Zanoni P, Thoelen A and Ybema S (2017) Unveiling the subject behind diversity: Exploring the micro-politics of representation in ethnic minority creatives' identity work.

Organization 24(3): 330-354. 
Figure 1: Autoethnographic, Relationally Reflexive Approach to Data Collection and Analysis

Project phases
1. Initiation
2. Exploring
ideas
3. Analysing
and
theorising

4. Developing
and refining
insights

Broader research group experience and identity formation

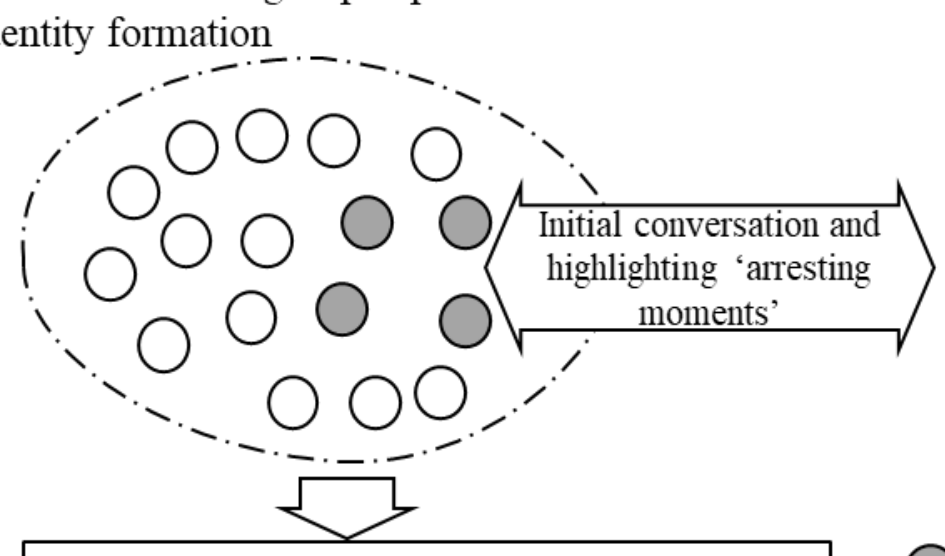

Further discussion among the authorial team followed by writing reflective narratives
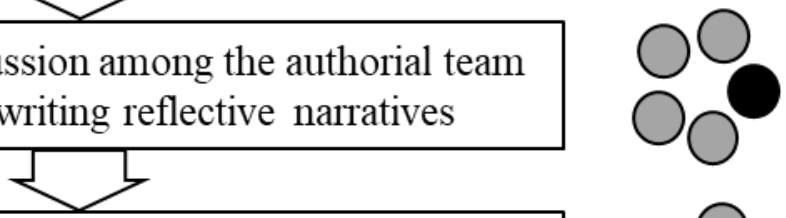

"Pair interviewing" to question, challenge, drill deeper; the external author acting as a sounding board.

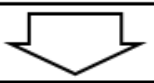

Questioning and challenging assumptions through ongoing discussions, presenting the ideas at seminars, conferences and through the review process

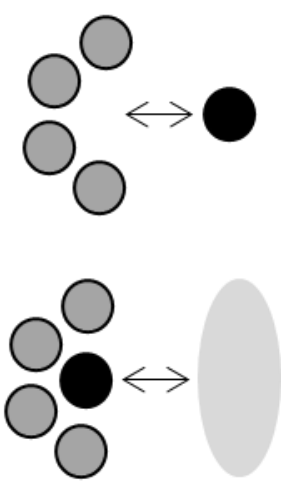

Authorial team

Other research group members

External audience 
Figure 2: The shadow side of the sheltering holding environment for identity work

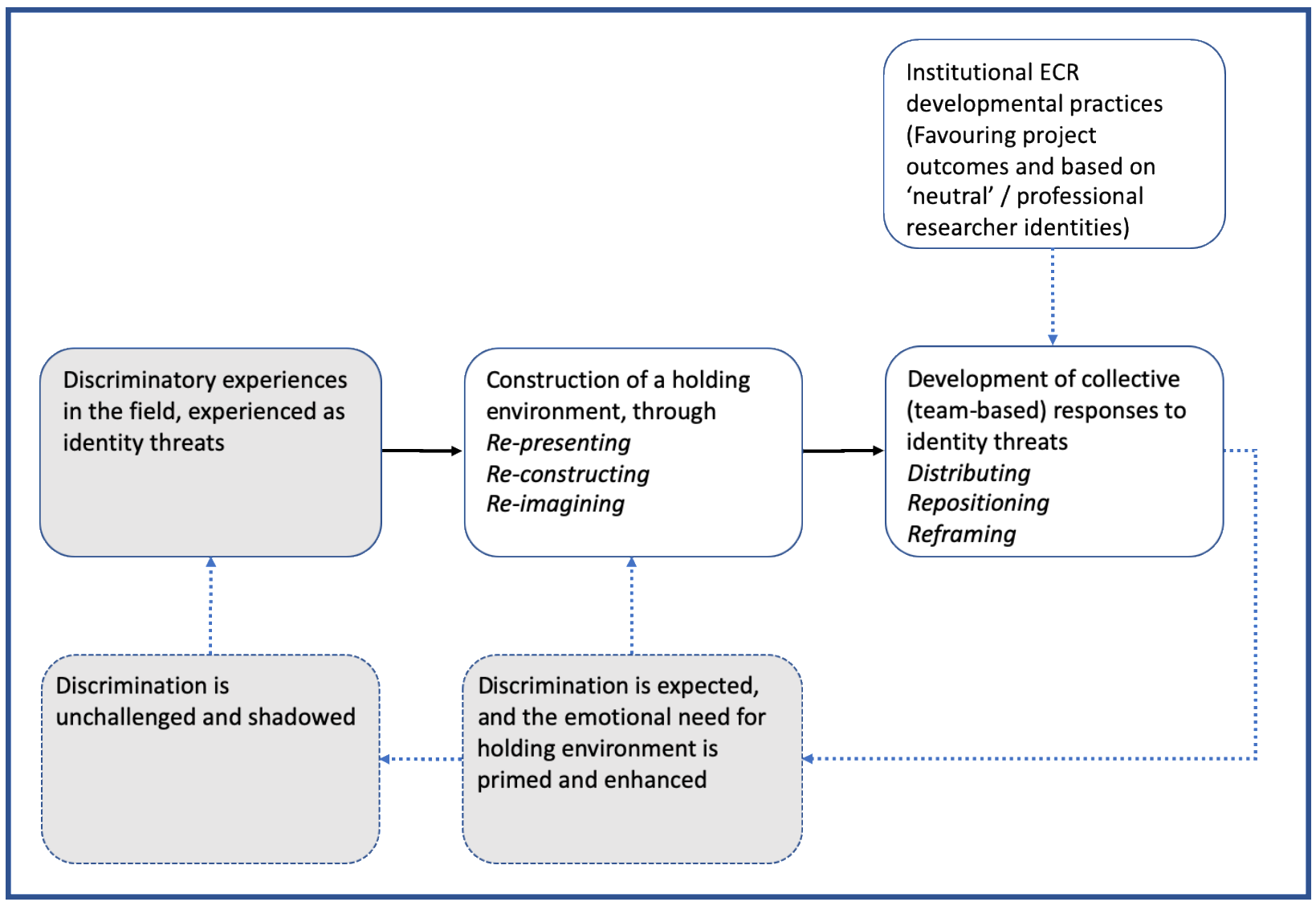

